THURSDAY, DECEMBER I, I88I

\section{THE ACCIDENTS IN MINES COMMISSION}

THE Preliminary Report of this Commission, recently 1 issued, affords a rather striking illustration of the amount of unpaid work which is occasionally done for the public by our busiest men. The Commission was appointed to inquire whether "the resources of science furnish any practicable expedients not now in use which are calculated to prevent the occurrence of accidents in mines or limit their disastrous effects." In its constitution science was represented by the following Fellows of the Royal Society :-Mr. Warington Smyth, Prof. Abel, Prof. Clifton, and Dr. Tyndall. The employers were represented by Sir George Elliot, M.P., Mr. William Thomas Lewis, and Mr. Lindsay Wood; the employed by the Member for Morpeth, Mr. Burt. Earl Crawford (then Lord Lindsay), who was added by a subsequent Royal Warrant, combined the man of science and the employer. $\mathrm{He}$ is a Vice-President of the Royal Society, and is largely interested in mining industry. Mr. Warington Smyth was very properly selected by the Home Secretary to preside over the Commission, for his scientific attainments are supplemented by varied and accurate knowledge of practical mining

The Commissioners set about their work in the most thorough manner. "In order to ascertain in what direction they could most usefully prosecute their inquiry," they "obtained the best possible evidence on the circumstances under which mines are worked, and on the acknowledged or probable causes of accident." They examined all the inspectors of mines, a large number of experienced colliery viewers and mining engineers, and a number of workmen selected by the miners' associations. They visited and inspected collieries in all parts of the kingdom, including most of those in which explosions of serious magnitude have recently occurred. At an early stage of their inquiry they found that they must make a series of extensive experiments, "involving much time and labour." They did not hesitate, they say, to "enter upon these experimental researches," and "there is good reason to hope," they add, "that their prosecution will result in the development, and perhaps in the settlement of, important questions bearing upon the elimination of accidents in mines."

In the meantime, as these experimental inquiries must necessarily take some time, they have thought it best to present at once the evidence which has been taken by them.

This evidence is preceded by a very interesting summary : One of the most important facts to which they draw attention is the great improvement which, so far as safety is concerned, has taken place during the last thirty years. Whilst the total number of deaths remains almost the same, the number of persons employed has nearly doubled, so that the fatalities have been reduced by nearly one-half.

These satisfactory results-as they point out in detailare due to the scientific treatment of the various problems involved in underground operations, and to the increased care and regularity exercised generally by workmen and officials in the daily routine of their work.

VOL. XXV.--No. 63I
The body of evidence which they have presented is full of interest and importance to all who are concerned in this great branch of our industry, whether as colliery owners, officials, or workmen. It has evidently satisfied the Commissioners as to the direction in which they must prosecute their inquiry, and as to the scientific problems which still remain to be solved. The source of danger which has hitherto defied all the efforts of science is the existence of light carburetted hydrogen gas-popularly known as "fire-damp" -in the coal. Falls of roof and side cause more than half the fatal accidents in mines. But a fall of roof never exacts more than one or two victims, and attracts scarcely any attention. The issue of fire-damp from the coal may-and often does-destroy hundreds of lives at a time, with a sudden, swift, and awful explosion, which strikes a natural terror into the whole mining population.

Wonderful as have been the recent improvements in ventilation, which are described in this Blue Book, the enormous volumes of air obtained by the best constructed furnaces or the most gigantic fans are unable to cope with the "sudden outbursts" of gas, which appear to increase in number as the deeper measures are reached. Recent experiments made by one of the Commissioners-Prof. Abel, at the request of the Home Office, and described in the summary-have revealed another danger, which improved ventilation may, under some circumstances, increase rather than diminish. From these experiments it appears that the presence of coal dust in the air of a mine renders it explosive if the air contains a proportion of firedamp so small that it cannot be detected by the most experienced observer with the means at present in use. Here it is that the Commissioners appear to consider that patient research and experiment may be of some avail. Fire-damp is harmless unless it be ignited. The only two ways in which it needs be ignited are by the lights used for lighting the mine and by the explosives used for driving headings and bringing down the coal. If a method of lighting could be devised which would not ignite an explosive mixture of fire-damp, all danger in that direction would be removed. If an explosive or other equally effcacious agent were devised which would not ignite such an explosive mixture, all danger in that direction would be removed. The Commissioners have had the electric light introduced experimentally at the Pleasley Colliery, near Mansfield. But though they say that an admirable illumination was obtained with Swan's electric lamps, they add that "further experiments and a full examination into all details connected with its application are needed before it can be decided whether the electrical illumination of workings is practically achievable."

With reference to the existing system of lighting by safety lamps, the Commissioners afford another instance of laborious inquiry. They found a powerful blower of natural gas at Mr. Smethurst's Garswood Hall Colliery, near Wigan. Here they had suitable apparatus put up, and made several hundreds of careful experiments with about fifty varieties of safety lamps, for the purpose of determining the relative safety of each variety. Not satisfied with those, they say it will be desirable "to carry on these experiments in further detail, and to repeat them in other localities with other varieties of fire-damp." We understand that the Commissioners have nearly completed 
arrangements for continuing these experiments at the Llwynpia Colliery of the Glamorgan Coal Company, where there is a large blower of natural gas.

On the subject of the other source of danger they make the following observations:- "The use of gunpowder and other explosives is at the present day so widely spread, and is held by many to be so indispensable, that all suggestions for checking their application in certain cases on account of risk need to be very carefully weighed." "An overwhelming majority of our witnesses assert that it is practically impossible, as a rule, to work mines without powder." They conclude however a review of the evidence on this subject with the following rather significant statement:-"In the meanwhile it has appeared to us to be desirable to make trials of such methods of 'falling' or bringing down the coal as may do away with the danger caused by sparks and flame; and with this view a series of experiments already commenced will be continued in different localities."

The result of these further inquiries and experiments with reference to lighting and blasting, it is of course impossible to forecast. We fear it would be rash even to hope for an announcement that for the future fiery seams may be worked with a light, and brought down by an explosive, neither of which can ignite an explosive mixture, and both of which can be readily adopted without adding to the cost of getting the coal. But we await with much interest the conclusion of an inquiry which has been conducted in such a thoroughly scientific manner, and upon which so much practical experience, time, and labour have been bestowed.

\section{CELESTIAL OBJECTS FOR COMMON TELESCOPES}

Celestial Objects for Common Telescopes. By the Rev, T. W. Webb, M.A., F.R.A.S. Fourth Edition, revised and greatly enlarged. (London: Longmans, Green, and Co., I88I.)

THIS is a new and much extended edition of a work 1 which has attained considerable popularity amongst the many amateurs of astronomy in this country who are limited to the use of instruments of moderate optical capacity, or as the author terms them, "Common Telescopes." By this term are intended achromatics with aperture of from three to five inches, or reflectors of somewhat greater diameter, yet as telescopes of higher pretensions are now in the possession of private observers, the author in the selection of additional objects has aimed at including such as may be considered tests for a superior class of instrument. The increase in telescopic range applying chiefly to the sidereal branch of astronomy, the additions have been taken for the most part from the works of the Struves and Burnham for double stars, and Sir John Herschel's catalogue for nebulæ: the total increase in the number of objects brought together in this new edition over the preceding one, is stated to be about $I_{500}$.

The first part of the work relates to the solar system, with a popular account of the actual state of our knowledge of the characteristics of its various members, so far as they fall within reach of moderate telescopes. In treating of the sun, the author collects many cases of the observation of dark spots in motion upon the disk, including that recorded by Mr. Capel Lofft of Ipswich, in January, I8I8, to which, if we mistake not, attention was first specially directed by $\mathrm{Mr}$. Webb in an earlier edition of the present work. He reproduces Pastorff's drawings of what he supposed to be the great comet of 1819 , in transit across the sun, on June 26 , taken from the originals, which are in the possession of the Royal Astronomical Society. The phosphorescence of the dark side of Venus, a phenomenon not as yet satisfactorily explained, is dwelt upon, as also the problematical satellite assigned to this planet. The moon is the subject of detailed description, the peculiarities of her surface, and the various craters, walled plains, valleys, clefts or rills, annular mountains, \&c., are brought together in an interesting form ; a map of the lunar surface forms the frontispiece to the volume, and a full index to the five hundred spots marked upon it, with an "Alphabetical Table of Lunar Nomenclature," is amongst the contents : indeed our satellite forms the subject of special treatment, which is amongst the most notable and useful features of $\mathrm{Mr}$. Webb's work. An outline chart of the surface of Mars follows, with the actual nomenclature, which we hope at no distant time to see placed upon a more satisfactory foundation. The principal points of interest furnished by telescopic observation of the disks of Jupiter and Saturn are referred to, though, from the limited space at disposal, in less detail than the reader might perhaps desire. Cases of visibility of the brighter satellites of Uranus, and the satellite of Neptune, with telescopes of moderate dimensions, are recorded.

After a brief notice of comets, the author passes to the main division of his work-sidereal astronomy, or, as he phrases it, "The Starry Heavens,-Double Stars, Clusters, and Nebulæ." In this division, as it appears to us, Mr. Webb is at a disadvantage in being compelled to employ a system of abbreviation which, in the eyes of some readers, will not be without its disadvantage : but he has been perfectly aware of this, and in his Introduction asks the reader "to excuse a condensed form of expression, the result of necessity rather than of choice"; the amateur who intends to make practical use of the work must therefore accustom himself at the outset to Mr. Webb's abbreviations, and it must be admitted that it would have been difficult, without some such system, to have given the amount of information which is contained in the 300 pages or less, devoted to stellar astronomy. Mr. Webb follows the convenient plan of taking the constellations in alphabetical order, so far as they are visible in these latitudes : telescopic objects in the southern heavens are only noticed in a short appendix. The positions of the various objects are given to the nearest minute of time only in right ascension and the nearest minute in declination, but it may be remarked that the former is not a suffi. ciently close indication of the places of several interesting objects which fall well within the scope of observation of many amateurs, whom it might be desirable to enlist for their more systematic observation. We allude to cases like that of Tycho Brahe's star of 1572, Kepler's star of 1604, or Anthelm's in 1670. For the former the author gives R.A. oh. 19m., Decl. $63^{\circ} 24^{\prime}$ N., and recommends that a minute star near the place should be watched; but any one acquainted wit' the neighbourhood will know that a 